\title{
A Rare Case of Contact Allergy towards Impression Compound Material
}

\author{
Wan Nor Syariza Wan Ali ${ }^{1}$ Nor Azura Ahmad Tarmidzi \\ 1Department of Conservative Dentistry and Prosthodontics, \\ Universiti Sains Islam Malaysia, Kuala Lumpur, Malaysia \\ ${ }^{2}$ Department of Oral and Maxillofacial Surgery, Pathology and \\ Medicine, Universiti Sains Islam Malaysia, Kuala Lumpur, Malaysia

\begin{abstract}
Address for correspondence Wan Nor Syariza Wan Ali, DDS, MClinDent, MPros, Department of Conservative Dentistry and Prosthodontics, Universiti Sains Islam Malaysia, Tower B, Menara MPAJ, Jalan Pandan Utama, Pandan Indah, 55100 Kuala Lumpur,
\end{abstract} \\ Malaysia (e-mail: wan_syariza@usim.edu.my).
}

\begin{abstract}
Keywords

- impression compound

- allergy

- hypersensitivity

Impression compound has been introduced for more than 100 years. Since then, it has been widely used to obtain a preliminary impression of the edentulous arch. Although the use of impression compound has declined markedly over recent years as newer materials have become available, the cost-effectiveness and desirable physical and mechanical properties make this material indispensable in developing countries and teaching institutions. Its high viscosity characterizes impression compound as a mucocompressive impression material, which enables the full depth of the sulcus to be recorded for the retention of complete dentures. Literature reviews revealed that most contact allergies to impression materials are towards polyether, very few are towards alginate and polysulfide, and no reported cases have been found toward impression compound. This case report demonstrates a recent rare case of contact allergy towards impression compound during a routine impression taking for a fully edentulous arch in a 61-year-old woman. The patient developed symptoms of an allergic reaction, and the management of the condition was described.
\end{abstract}

\section{Introduction}

Hypersensitivity responses are a collection of reactions where the immune system plays a defensive role but produces damaging results. Hypersensitivity can be triggered from endogenous self-antigen or exogenous antigens such as microbial or nonmicrobial components. ${ }^{1}$ An allergy is a common reaction developed from body reactions to exogenous antigens. Hypersensitivity is classified based on the antigens' mechanism of action (-Table $\mathbf{1}$ ).

Dental materials that are placed in contact with oral mucosa should be ideally biocompatible to minimize the body reaction towards the materials placed intraorally. Patients undergoing dental treatment can be exposed to a

published online August 12, 2021
DOI https://doi.org/ $10.1055 / \mathrm{s}-0041-1731584$ ISSN 1305-7456 wide range of potential allergens. The most common materials that can trigger the development of allergic reactions in dental patients are amalgam, nickel-chromium, resin in composite, and local anesthesia. ${ }^{2}$ Evidence on impression materials that can cause allergic reactions is limited, particularly on impression compound. ${ }^{3,4}$ Contact allergic reactions (type IV hypersensitivity reaction) are the most common side effects to prosthodontic materials. ${ }^{5}$

The clinical manifestations of contact allergy to dental materials are not uniform. It can cause cheilitis, gingivitis, stomatitis, perioral dermatitis, burning mouth syndrome, lichenoid reaction, and orofacial granulomatosis. ${ }^{6}$ The dental practitioners must always be aware of the possibility that patients might experience allergic reactions during

\footnotetext{
(C) 2021. European Journal of Dentistry.

This is an open access article published by Thieme under the terms of the Creative Commons Attribution-NonDerivative-NonCommercial-License, permitting copying and reproduction so long as the original work is given appropriate credit. Contents may not be used for commercial purposes, or adapted, remixed, transformed or built upon. (https://creativecommons.org/licenses/by-nc-nd/4.0/).

Thieme Medical and Scientific Publishers Pvt. Ltd. A-12, 2nd Floor, Sector 2, Noida-201301 UP, India
} 
Table 1 Overview of hypersensitivity

\begin{tabular}{|l|l|l|l|}
\hline Type & Immune reactant & Reaction & Examples \\
\hline Type I hypersensitivity & IgE & $\begin{array}{l}\text { Inflammation, edema, } \\
\text { eczema, diarrhea }\end{array}$ & $\begin{array}{l}\text { Anaphylaxis, drug allergy, food allergy, } \\
\text { asthma, angioedema }\end{array}$ \\
\hline Type II hypersensitivity & Antibody, IgG, IgM & Paralysis, anemia, nephritis & $\begin{array}{l}\text { Hemolytic disease of the newborn, } \\
\text { Goodpasture syndrome, drug sensitivity }\end{array}$ \\
\hline Type III hypersensitivity & $\begin{array}{l}\text { Immune complexes, baso- } \\
\text { phil, complement }\end{array}$ & $\begin{array}{l}\text { Joint inflammation, } \\
\text { nephritis }\end{array}$ & $\begin{array}{l}\text { Serum sickness, systemic lupus } \\
\text { erythematosus }\end{array}$ \\
\hline Type IV hypersensitivity & T cells, macrophages & Skin inflammation & Delayed hypersensitivity (e.g., amalgam) \\
\hline
\end{tabular}

Abbreviation: Ig, immunoglobulin.

Source: Adapted from Basu and Banik.

dental treatment. In a well-established allergic condition, the patient will inform the dental practitioners of their history, and it is the responsibility of the dental practitioners to ask in detail about this information.

\section{Clinical Report}

A 61-year-old woman presented at the dental undergraduate prosthodontics clinic for construction of upper and lower complete dentures. Medical history revealed that the patient has well-controlled diabetes mellitus and hypertension. Patient claimed she complied to medications prescribed and underwent regular follow-ups at the hospital. She has no known allergies and no significant history of hospitalization. The patient is fully edentulous since the past 2 years but never worn any dentures before.

Routine primary impression was taken on the upper arch for construction of the complete dentures using impression compound (Hoffmann Dental Manufaktur GmbH, Germany) and metal stock tray. One hour after the first impression compound exposure, the patient complained of itchiness and discomfort at the palate and inner upper lip. Intraorally, multiple petechiae were observed at the area of mucosa that was in contact with the impression compound ( - Fig. 1). A few hemorrhagic vesicles were also noted at the palatal and alveolar mucosae ( $\boldsymbol{- F i g}$. 2). The mucosa covering the palate appeared erythematous with a clear demarcation of healthy mucosa and the affected mucosa at the posterior part of the

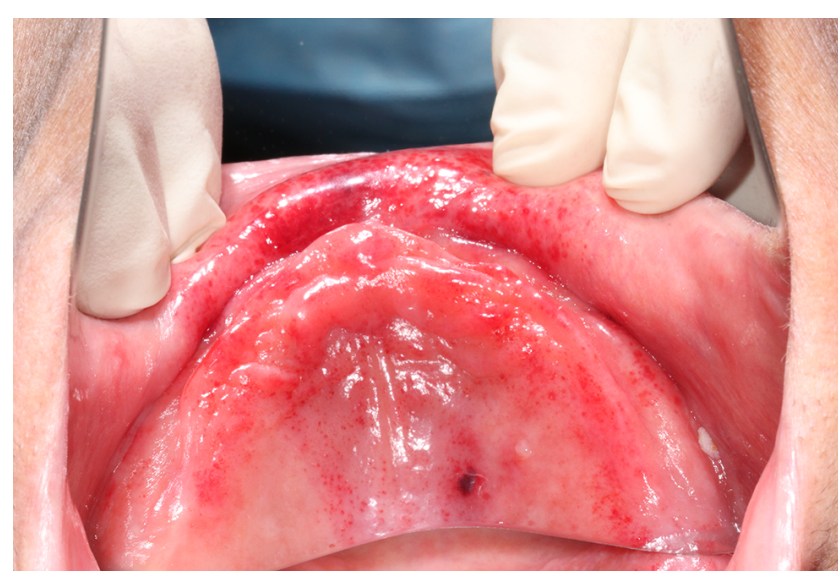

Fig. 1 Multiple petechiae at the area of mucosa that was in contact with the impression compound. palate ( - Fig. $\mathbf{3}$ ). No signs and/or symptoms were noted on the lower edentulous arch and lower lip and extraorally. Patient did not complain of difficulty in breathing or any symptoms elsewhere on the body. Vital signs were within normal range.

A diagnosis of allergic reaction was concluded, and the patient was prescribed with antihistamine, topical hyaluronic acid, and Difflam mouthwash. The patient was

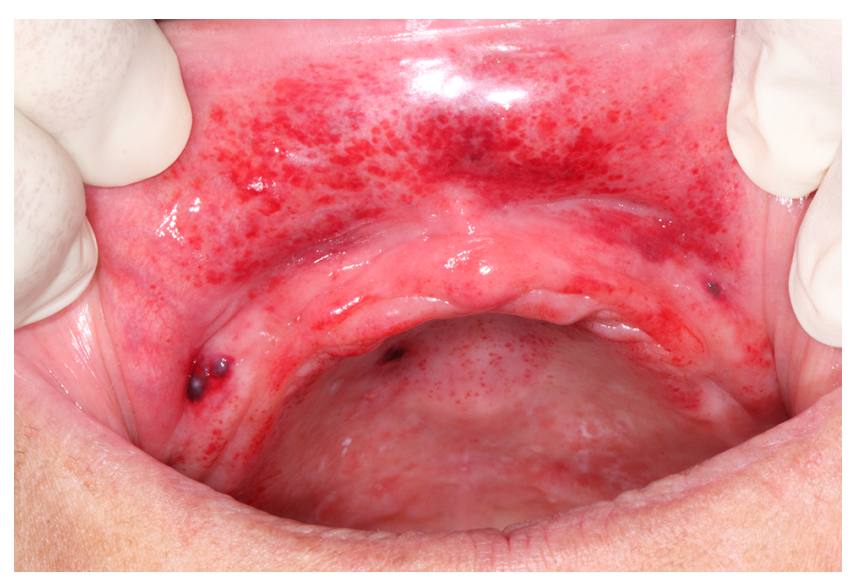

Fig. 2 Hemorrhagic vesicles were also seen at the palatal and alveolar mucosae.

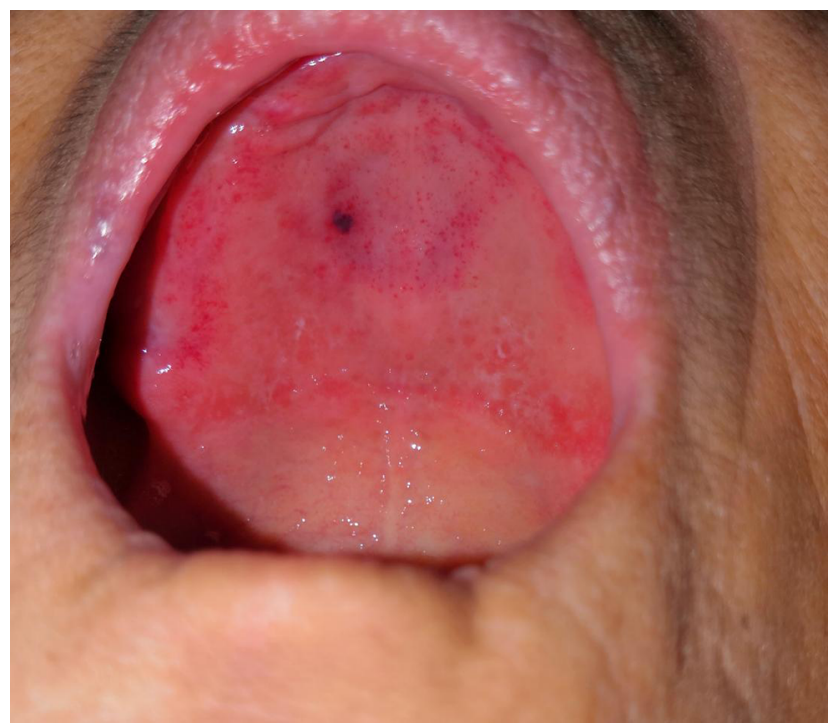

Fig. 3 The mucosa covering the palate appears erythematous with a clear demarcation of healthy mucosa and the affected mucosa at the posterior part of the palate. 
advised to take soft diet for at least 3 days and to take care of her oral hygiene to prevent superinfection of the lesion. The patient was given an appointment for review after 2 days; unfortunately, she did not comply. Intraoral photographs were obtained 30 minutes after the first initial complaint, with informed consent. A phone call follow-up was made 1 week after the incident, and the patient claimed that the lesions subsided after 1 day. A referral to the nearest hospital for patch test was arranged after the incident. A subsequent appointment could not be made due to the implementation of lockdown because of COVID-19 pandemic.

\section{Discussion}

The oral cavity is exposed to many materials that can cause an allergic reaction, but allergies specifically toward impression materials are rare. ${ }^{2}$ Even though the material is only in contact with the mucosa within minutes, it is still able to trigger such reactions. The spectrum of clinical manifestation of these allergic reactions is broad and can range from urticaria, rash, and swelling to life-threatening conditions such as anaphylactic shock. Fatalities due to allergic reaction after exposure to impression materials had been reported; however, the reported case of death was believed to occur due to the presence of a comorbid disease. ${ }^{7}$

In this case, routine primary impression of the fully edentulous area was taken using type I impression compound on a stock tray to obtain a mucocompressive impression of the upper arch. Impression compound was introduced in the 1800 s, and it is considered the most vicious, thermoplastic, and rigid impression material in the field. The high viscosity of impression compound enables it to become mucocompressive, making it capable of displacing the lingual and buccal soft tissues sufficiently to record the full depth of the sulcus for retention of the denture.

Impression compound is composed of $47 \%$ of thermoplastic materials from natural or synthetic resin and waxes to characterize the softening temperature, talc as filler (50\%) to give body by increasing the viscosity of the softened material and reduce thermal contraction and stearic acid as lubricant (3\%) to improve the flow properties. ${ }^{8}$ The difference in its thermoplastic components resulting in two types of impression compounds: type I (lower fusing temperature, usually used for impression material) and type II (higher fusing temperature, usually used for the construction of impression tray). One of the main properties of type I impression compound is its ability to flow at just above the mouth temperature and record the edentulous arch, and the material comes in sheets and needs to be softened using a warm water bath.

In this case, after 1 hour of contact with type I impression compound, the patient started to experience symptoms such as itchiness and discomfort intraorally. As the patient has not had any dentures before, therefore, she had no exposure to impression compound prior to the incident. The rapid onset as well as more widespread response may suggest type I hypersensitivity reactions, even though it is difficult to be verified as most cases of contact stomatitis are classified as delayed hypersensitivity (type IV). ${ }^{4}$ However, the precise nature of these acute allergic responses is unclear. Type I hypersensitivity is the immediate hypersensitivity caused by immunoglobulin E (IgE) antibody, and it can be either systemic or local. ${ }^{1}$ Type IV hypersensitivity or delayed type hypersensitivity is a cell-mediated response that is incorporated with sensitized $\mathrm{T}$ helper cells. The period course in type IV hypersensitivity usually takes 12 to 24 hours to progress and persevere for 2 to 3 days. ${ }^{1}$ Clinical features of the allergic response can be used to distinguish whether the reaction is acute or chronic, as shown in - Table 2.

In prosthetic allergic stomatitis, lesions of this stomatitis are found in the form of erythema, edema, vesicles, bullae, erosions, and ulcerations. ${ }^{6}$ The lesion is localized in the area of contact with the source, which is the impression compound in this case. Stomatitis can also sometimes appear as an area of swelling and small erosions in multiple forms. ${ }^{6}$ For the current case, the patient's mucosa appeared to have petechiae and hemorrhagic vesicle, which are rarely seen in cases of other contact stomatitis. Otherwise, the patient complained of pain at the affected area. The cause in this case is highly unlikely to be due to thermal injury; in such cases, the clinical appearance would be red or white painful erythema that may undergo desquamation, leaving an area of erosions and necrosis. ${ }^{9}$

Considering that impression compound has been in use for more than 100 years, surprisingly, no incidence of allergic reactions toward impression compound has been reported in any works of literature. Most of the literature revealed that impression materials containing polyether were the most common cause of allergic reactions to patients, ${ }^{4}$ and isolated reports of allergic cases from polysulfide and alginate materials were noted. ${ }^{2}$ One of the main reasons for the allergic reaction is the leaching of any of the materials' constituents into the oral mucosa; in this case, leaching any of the constituents can follow the conditioning of impression compound in a water bath. The temperature and time of conditioning in the water bath are crucial to maintain the properties of impression compound and avoid leaching of its composition. The ideal temperature for conditioning of the impression compound is between 55 and $60^{\circ} \mathrm{C}$; long conditioning time

Table 2 Characteristics of contact allergy toward dental materials ${ }^{14}$

\begin{tabular}{|l|l|l|}
\hline Onset & Chronic & Acute \\
\hline $\begin{array}{l}\text { Type of } \\
\text { hypersensitivity }\end{array}$ & $\begin{array}{l}\text { Gradual (may be } \\
\text { years after chronic } \\
\text { exposure) }\end{array}$ & $\begin{array}{l}\text { Within minutes to } \\
\text { hours of exposure }\end{array}$ \\
\hline Duration & $\begin{array}{l}\text { Prolonged (as } \\
\text { long as mucosa in } \\
\text { contact with the } \\
\text { dental material) }\end{array}$ & $\begin{array}{l}\text { Resolves spontane- } \\
\text { ously within days }\end{array}$ \\
\hline $\begin{array}{l}\text { Example of oral } \\
\text { condition }\end{array}$ & $\begin{array}{l}\text { Lichenoid reac- } \\
\text { tions, erythema } \\
\text { multiforme (oral } \\
\text { manifestation) }\end{array}$ & $\begin{array}{l}\text { Angioedema, } \\
\text { stomatitis }\end{array}$ \\
\hline
\end{tabular}


or high conditioning temperature will lead to leaching of its constituents, such as stearic acid. ${ }^{8}$

In reaching the diagnosis of allergic stomatitis, it must be distinguished from the possibility of toxic/irritant reaction. Therefore, a patient must be asked of any allergies toward any material or food during history taking. By knowing this information, exposure of possible allergens can be reduced or prevented to avoid such allergic manifestations in the dental clinic. Treatment for allergic stomatitis includes removal of suspected allergens, topical or systemic corticosteroids, and antihistamines. ${ }^{9}$

Patch test for patients who develop allergic reactions after exposure to any dental materials should be conducted to confirm the diagnosis of contact dermatitis/stomatitis. ${ }^{10}$ Patch test is a useful, simple, noninvasive method to detect contact allergies in patients and dental personnel. ${ }^{11}$ The standard method involves the application of antigen to the skin at standardized concentrations in an appropriate vehicle, and it is considered the mainstay of diagnosis in allergic contact dermatitis. ${ }^{12,13}$ However, no significant findings was noted from the patch test of the patient. Studies has shown that not all cases with hypersensitivity presented with significant findings in patch test, as type I hypersensitivity responses are more suitable to be tested by using the in vitro radioallergosorbent test for antigen-specific IgE antibodies or by skin prick testing. ${ }^{14}$

\section{Conclusion}

Cost-effectiveness and desirable physical and mechanical properties of impression compound as a mucocompressive impression material make this material indispensable in developing countries. Even though an allergic reaction toward impression compound is considered rare, the chances of any patient becoming sensitive to the material must not be taken lightly. Therefore, proper handling of the materials and thorough history taking including patients' previous experiences and medical history before any procedures are important during any procedure in medicine and dentistry. Several tests need to be conducted to confirm and determine the etiology of a patient's allergic reaction.

\section{Conflict of Interest}

None declared.

\section{References}

1 Basu S, Banik BK. Hypersensitivity: an overview. Immunol Current Res 2018;2(1):105

2 Syed M, Chopra R, Sachdev V. Allergic reactions to dental materials-a systematic review. J Clin Diagn Res 2015;9(10):ZE04-ZE09

3 Manoharan PS. A rare case report of a patient with allergic reaction following use of a dental impression material. Int J Med Dent Case Rep 2017;2:1-3

4 Mittermüller P, Szeimies RM, Landthaler M, Schmalz G. A rare allergy to a polyether dental impression material. Clin Oral Investig 2012;16(4):1111-1116

5 Padmaja S. Biohazards associated with materials used in prosthodontics. Niger J Clin Pract 2013;16(2):139-144

6 Bakula A, Lugović-Mihić L, Situm M, Turcin J, Sinković A. Contact allergy in the mouth: diversity of clinical presentations and diagnosis of common allergens relevant to dental practice. Acta Clin Croat 2011;50(4):553-561

7 Gangemi S, Spagnolo EV, Cardia G, Minciullo PL. Fatal anaphylactic shock due to a dental impression material. Int J Prosthodont 2009;22(1):33-34

8 McCabe JF, Walls A, Applied Dental Materials. Oxford, UK: Blackwell Pub; 2008:147-154

9 Koray M, Tosun T. Oral Mucosal Trauma and Injuries. In Trauma in Dentistry. IntechOpen 2019. Available at: https://cdn.intechopen.com/pdfs/65714.pdf. Accessed January 10, 2021

10 Raap U, Stiesch M, Kapp A. Contact allergy to dental materials. J Dtsch Dermatol Ges 2012;10(6):391-396, quiz 397

11 Rai R, Dinakar D, Kurian SS, Bindoo YA. Investigation of contact allergy to dental materials by patch testing. Indian Dermatol Online J 2014;5(3):282-286

12 Bourke J, Coulson I, English J; British Association of Dermatologists. Guidelines for care of contact dermatitis. $\mathrm{Br}$ J Dermatol 2001;145(6):877-885

13 Gawkrodger DJ. Investigation of reactions to dental materials. Br J Dermatol 2005;153(3):479-485

14 McGivern B, Pemberton M, Theaker ED, Buchanan JAG, Thornhill MH. Delayed and immediate hypersensitivity reactions associated with the use of amalgam. Br Dent J 2000;188(2):73-76 